Review

\title{
Exploration of an Ethical Quagmire: The Doctrine of Double-Effect in Neonatal Palliative Care
}

\author{
Victoria J Kain ${ }^{1 *}$ and Joana Mendes ${ }^{2}$ \\ 1 School of Nursing and Midwifery, Griffith University, Queensland Australia; \\ v.kain@griffith.edu.au \\ 2 São Francisco Xavier Hospital, Lisbon, Portugal; joanaccmendes@hotmail.com \\ * Correspondence: v.kain@griffith.edu.au.
}

\begin{abstract}
:
Neonatal palliative care (NPC) is an integrated and holistic approach that is an integral part of the contemporary neonatal treatment delivery paradigm. It is the highest fulfillment of the notion of beneficence (doing or creating 'good') that has otherwise been neglected/underestimated by the focus of modern medicine on technology and instrumental treatments by its commitment to alleviating patient pain and quality of life.
\end{abstract}

For decades, the Double-Effect Doctrine (DDE) has been used to consider and address a range of ethically questionable circumstances, often at the end of life, including euthanasia, termination of pregnancy to save maternal life, and morally justified warfare.

The theory has continued to be mired in controversy as ethicists, legal scholars, theologians, and philosophers discuss the abstract concepts of moral reasoning, purpose, foresight, and other underlying moral theories.

In this paper, the moral theory of DDE is discussed in its clinical application to the ethical decision-making process in neonatal palliative and end-of-life treatment, specifically 1) the administration of opioids as required for symptom control and 2) the use of palliative sedation for intractable symptom care.

Keywords: neonatal palliative care; Doctrine of Double Effect; perinatal palliative care; neonatal end-of-life care

\section{Introduction}

Palliative care represents the highest fulfillment of the concept of beneficence (doing or producing 'good') which has been otherwise neglected/undervalued by modern medicine's emphasis on technology and instrumental therapies, through its specific commitment to the alleviation of patient suffering and quality of life. The focus of palliative care led to new challenges when applying 'traditional' principles of medical ethics. Ethical discussions can be extremely complex, especially in scenarios of uncertainty at end of life care.

In palliative care, the 'openness to care' is based on an appreciation of the fragility of the independent self and the possibility of preserving 
personal independence while being dependent on others. The neonatal population at the end of life stands as a paradigmatic example of extreme vulnerability [1]. However, the ethics of palliative care it is not merely a question of reformulating the equilibrium between separate ethical values in dilemmatic decision making, with unexpected life or death outcomes. This is where the Doctrine of Double-Effect (DDE) historically has been applied.

DDE has been used for centuries in contemplating and debating a number of ethically ambiguous situations mostly at the end of life, including euthanasia, termination-of-pregnancy to save maternal life, and warfare that is morally justified. It is a 'moral concept' taken from the teachings of Saint Thomas Aquinas (c.1224-d. 1274 CE), a Catholic theologian in the 13th century.

Since ethicists, legal theorists, theologians, and philosophers debate the abstract principles of moral reasoning, purpose, foresight, and other underlying moral theories, the Doctrine has continued to be mired in controversy.

In this paper, the moral theory of DDE in its clinical application to the ethical decision-making process in palliative and end-of-life care for neonates will be discussed, specifically 1) the administration of opioids as needed for symptom control and 2) the use of palliative sedation for intractable symptom care.

Neonatal palliative care (NPC) is an involved and holistic approach that is an important part of the delivery model of contemporary neonatal treatment and should be provided throughout an entire hospital system. Before, at, or after birth, regardless of where in the facility the contact with family is made, when in the pregnancy the loss occurs, or whatever the conditions are that contribute to the pregnancy ending [2], this active type of treatment starts once a life-limiting, terminal or uncertain condition has been determined/diagnosed. It requires a purposeful and planned approach to care involving a joint family decision-making and a multidisciplinary team, trained to provide bereavement support and effective palliative symptom management.

The advantages of curative treatments are carefully considered and weighed with the advantages of a move towards palliative treatments as the infant's path unfolds. In a scenario of uncertainty, parallel planning should be considered since the diagnosis and all the medical decisions should be revisited as needed. In this challenging decision-making process, the parent's desires are important and one of the overriding factors in assessing the suitability of therapies, whether curative or palliative in nature. A palliative care model's core component provide support for the family that meets their moral, cultural and psychosocial needs. Treatment includes relieving discomfort through adequate pain diagnosis and treatment, managed therapies, and treating distressing symptoms during the dying process. Good neonatal palliative care provides counselling for the family before and after their child's death. An integral component of NPC is memory making that will later aid in the mourning process. Follow-up treatment including referrals to support services and bereavement groups is important to the family's 
grieving process and long-term mental and physical wellbeing [3]. The primacy of ensuring that quality of life is at the heart of NPC, while offering ethical and humane treatment that facilitates 'a good life until death'.

\section{Locating the Doctrine of Double-Effect in Contemporary Practice}

Aquinas' premise held that ... 'nothing hinders one act from having two effects, only one of which is intended, while the other is beside the intention.... Accordingly, the act of self-defense may have two effects: one, the saving of one's life; the other, the slaying of the aggressor'.

In his discussion of the permissibility of killing in self-defense, originally formulated by 'double-effect logic', the Doctrine relies on three simple arguments. The first is objective and essentially noncontroversial, which can have many implications for single actions, some good, some bad. The second is a philosophical argument that is arguably fundamental to the Western medical tradition, that we are obligated to avoid doing harm in the first instance (non-maleficence). The third is metaphysical, and more controversial: that as a consequence of our actions, there is a true and not merely verbal difference between what we expect and what we anticipate [4]. It is this aspect of the Doctrine that concerns this paper, and how it might apply to neonatal palliative care.

Although the theory has traditionally been explored in the most severe situations, it has been stated that, in practice, all therapies and procedures bear some inherent risk of foreseeable negative effects [5]. The DDE has been used to argue that a general opposition to termination-of-pregnancy is consistent with allowing cases of termination-of-pregnancy, such as when the life of the mother is endangered. One such disorder is tubal ectopic pregnancy. In these cases, to save the mother's life, the diseased Fallopian tube must be removed, which, moreover, means that the fetus is then removed and, therefore, a termination-of-pregnancy is performed. It has been argued, however, that the conventional DDE still allows this, because aborting the fetus is not an expected consequence of extracting the diseased tube, but merely a foreseen side effect of doing so [6]. The same principal may apply to administering a medication to a newborn who is not expected to survive, and even when administered with a good intention and from a sound evidence base, we cannot be certain that the newborn will not have a life-threatening reaction to that medication.

A recent systematic review by Gannon in 2019 [7] found both positives and negatives in the modern medical applicability of DDE: Positives: legal prerequisites (realizing morbidity/mortality of treatment); essential moral 'instruments' (clinicians need 'good intentions'). Negative: needless (no legal/clinical need); misinformed fears (fueled by unfounded opioid fears); paternalistic medical perspectives (personal, not patient-centered); unusable (complex, and untestable intention/motive); risk of deviation from customized dosing (poor technique, even if well-meaning); it should not be a blanket 'doctrine' (or 'untouchable' protection against opioids being mis-prescribed). 
In certain environments, DDE has been condemned as being a term so amorphous as to no longer be consistent as a philosophical guiding principle [8]. Controversy has traditionally centered around this ethical principle; its use and validity has been discussed by ethics theorists and bedside clinicians alike. Some assume that DDE is a general axiom, a concept on which all medical treatment is based. While the concept enables the increased use of analgesia and sedation to control pain even though it shortens life, healthcare providers must ensure that their acts cannot be viewed as driven by a desire to cause the patient to die when prescribing prescribed medications to alleviate pain in palliative care. Such an action is illegal and could lead to a murder charge [9].

Together, the DDE is formulated as a set of four criteria that must be fulfilled for any act of both good and bad consequences if that act is to be morally justified. The first condition is that the act must not be necessarily incorrect in itself. In the instance of palliative care, this will be the act of providing pain relievers. Clearly, there is nothing fundamentally wrong with pain-relieving medication administration. The second condition is that it must not be meant to have the wrong effect. Again, the purpose of the caregiver must be to alleviate discomfort, not to kill the patient, in the classic case of palliative care. The third criterion stipulates that the means to the positive result must not be the poor effect. Even if palliative administration could hasten the death of a patient, considering death as an end to all misery, shortening the life of a patient is not a means to that end. The fourth criterion is that the bad impact on the intended good is not disproportionate. If the administration of a medication for pain follows best practice principles and only has the intention to promote comfort, the 'good' outweighs the potential 'bad' of a shortened life [4].

As it has long-informed Western medical practice, double-effect logic is wrongly familiar to most clinicians, most recognizably in end-of-life contexts, where it is usually used to justify the delivery of palliative care. There is a strong belief that high doses of opioid analgesics to promote pain relief can interfere in the moment of death.

\section{Critical Care Decisions in the Newborn Care Unit}

Palliative care is a human right and the World Health Organisation underlies the responsibility of nations to provide universal health coverage throughout the life cycle. The neonatal population is the most prevalent, representing almost $40 \%$ of children in need of pediatric palliative care worldwide [10], and children under the age of one with a life limiting condition are rising each year [11].

Perinatal hospice and palliative care lists more than 300 programs in $8 \%$ of the globe. There is still an important lack of service provision, education and guidelines [12]. In the developed countries, neonatal palliative care and end of life care often occurs in the intensive care setting. Most healthcare clinicians working in neonatal intensive care do not undergo any mandatory palliative care training and there is restricted access to those who are specially qualified in palliative care [13]. In Europe, research conducted by Arias-Casais et al [14] found that only 7 of 54 countries had specific neonatal palliative care referral 
services. This means that many neonates who may benefit would not necessarily have access to sufficient palliative care and indicates that if and when palliative care fails to alleviate pain, the morally relevant question of what the duties of caregivers are to the suffering to the newborn are inevitable.

If suffering is multidimensional, more complex than physical pain and evokes the capacity of self-awareness, how can we measure neonatal suffering? When we affirm that a newborn has intractable suffering what does this really mean? Is this suffering the mirror of the adults own suffering, professionals and parents? For Fortney and Steward [15] the awareness of a good neonatal death is related on one side, with the health care expectations (based on their clinical expertise and evidence based approach) coupled with the parent's perception about neonatal symptoms (embedded on their values, wishes and cultural background). And what suffering can be avoidable in neonatal care? Symptom control, bonding and physical contact with the mother are examples of comfort measures that optimize quality neonatal care.

If the obligation to provide palliative care derives from a more general duty to alleviate suffering, then on what grounds can the only remaining option for relieving the suffering of a newborn in such cases be deemed to be morally impermissible, namely a swift and painless end to life? Palliative care, however, for any patient population is meant to alleviate symptoms and pain, not to bring the time of death forward. Palliative care respects life until the end, focusing on the quality of life and do not interfere actively in the moment of death [16]. Although this position is sustainable in the palliative stage, it has been argued that in the terminal stage, when death is inevitable, this position is likely to be questioned (when death is hours or days away). Clinicians should understand that decreasing life-sustaining care and terminal sedation can also alter the time of death as death approaches, although this matter cannot be clinically confirmed, one way or the other, in a specific case, or in general [17].

The Nuffield Council on Bioethics' Critical care decisions in fetal and neonatal medicine [18] made a valuable contribution to the discussion of decision making in the critical care of neonates. In opposing active euthanasia as morally impermissible, the Nuffield study maintained that there was, and is, a responsibility to offer palliative treatment to newborns suffering in terminal cases. Palliative care may include withholding or withdrawing medical interventions, that will do more harm than good, and sedation to relief refractory symptoms as needed [16].

April and Parker [19] identified a 'slippery slope' in the Nuffield Report [18], claiming that three other statements must also be held for this argument to work: first, that in adults non-voluntary euthanasia is morally impermissible; second, that in chronic vegetative conditions, there are no morally significant distinctions between newborns and adults; and third, that there is no appropriate legislative or other mechanism available to preserve the distinction. The Nuffield report argues that the burden of proof for showing morally valid differences falls on those who seek to argue against the stance of the report, instead 
of seizing the opportunity to test these claims. In its second moral statement, the study states that, even in the case of suffering newborns for whom palliative treatment has failed, DDE makes intentionally hastening death morally impermissible.

To return to the primary concept of the DDE, it holds that actions with one bad outcome and one good outcome can be morally acceptable if the good outcome is expected, even if foreseen, while the bad outcome is not intended. In a working party cited in April and Parker [19] the DDE argued that it was morally permissible for clinicians to prescribe palliative care that hastens the death of a child, but that it was impermissible for them to administer an opiate dose that would result in death. What made the moral distinction between the two cases is that the clinician merely foresaw that the procedure would hasten death in the case of administering pain relief medicine, while the clinician necessarily intended to end life in the case of a lethal opiate dose. The DDE is a powerful intellectual instrument that is useful in the sphere of law and in allowing those with clear moral values to behave with compassion; however, it is not unproblematic to use it in the sense of neonatal treatment. For it changes the central moral question from concern about the irremediable suffering of the newborn, which is the basic ethical concern on which much of the study was based in April and Parker's paper, to concern about the moral status of the intentions of the clinician. In view of the Nuffield report's assertion that the needs of the infant are the most significant ethical factors in decision-making on critical care, a prolonged discussion on whether a change in moral focus from those interests to the intentions of the clinician was acceptable and may have proven fruitful. The authors argued that this discussion could have altered the final position of the working party [19].

In terms of critical care decisions in neonatal care, Genuis [20] suggests two reasons why the DDE has been used less in the latter half of the twentieth century, hence why its application may be problematic in neonates: First, several studies have shown that it is impossible that suitable palliative sedation would potentially shorten life (this will be further discussed). Second, for those who take ethics in neonatal care seriously (and one would hope this is the entire multidisciplinary care team), the DDE is compelling: It leads us to the much-discussed distinction between Kantian ethics (a duty to do the 'right thing', even if it produces a bad result) and Mill's utilitarianism (actions are 'right' in proportion to promote happiness, 'wrong' if they produce the reverse of happiness). In-depth debate on these principles is beyond the scope of this paper, however Genuis argues that our ethics have become increasingly utilitarian, over the past 50 years, and therefore the moral distinction suggested by the DDE has appeared less and less distinct. The DDE no longer offers a crucial distinction to explain a distinct philosophy of palliative care if intent does not have an influence on ethics [20].

\section{The 'Devils' Choice'}

Decision making for neonates who are not expected to survive due to extreme prematurity, birth defects and other life-limiting conditions is 
complex and may be fraught with ethical dilemmas. Magnusson [21] referred to the 'devils' choice' when making decisions re life-supporting technologies being withdrawn from suffering neonates who are not expected to survive. The 'devils' choice' is a metaphor for many end-oflife healthcare clinicians who offer palliative care, including in newborn care. It can occur, first of all, with the provision of opioid analgesics to alleviate pain and symptoms, in circumstances where the clinician expects/are afraid that these narcotics may impair the breathing or cough reflex of the patient and cause fluids to accumulate in the lungs in a manner that leads to earlier death. When prescribing the dosages charted by the doctor, nurses in particular may face this dilemma, often in the absence of the doctor, based on their own knowledge of the effects of analgesics and sedating agents on distressed patients who are in a seriously weakened state [21].

Secondly, when the technique for the management of refractory pain or symptom relief applied to terminally ill patient is, in practice, sedation, the 'devils' choice' can arise - intractable pain or discomfort is managed by keeping the patient unconscious, with or without continued hydration and nutrition administration. Palliative sedation in end of life is/can be ethically controversial and continues to be so. Since the predictable outcome/ undesirable consequence of certain symptom relief practices might be a hastened death, the dividing line between 'palliative care' and 'unethical killing' is crucially essential, both ethically and legally. Neonatal euthanasia is legal in the Netherlands [22] and in a Belgium study it was concluded that physicians and nurses feel that it is acceptable, in certain cases, to administer medication with the explicit intention of hastening death [23]. Public faith in the medical profession and in the field of palliative medicine requires that we differentiate between clinicians and murderers, and healthcare deserves the clearest guidance about what distinguishes lawful from unlawful conduct [21].

Clearly, the 'devils' choice' raises legal as well as ethical concerns. Universally, Westernized legislation attempts to prevent criminalizing medical behavior that is acceptable. The law tends to take a common sense and multifactorial view of causation while discussing such issues, and may sometimes not even apply a causal examination, concentrating instead on the validity of acts and the existence or absence of duties.

While many are required to draw on the DDE as a medico-legal guideline, many have also reported its inadequacy. As a simplified and generic guideline, the DDE has been established as a convenient method to protect those who have unintentionally or deliberately accelerated death. But its minimal emphasis on the intent of the clinician illuminates how easily it can be abused, thus impairing transparency and a capacity for honesty [24]. In the UK [9] under the DDE, the legislation controlling the proper use of controlled substances to relieve pain is simple. If there is any indication that the prescriber/conduct administrator's is motivated by causing the death of the patient and not merely to alleviate pain, then a murder or attempted murder charge could result. It is critical that those who prescribe and administer opiates carefully and accurately monitor their use of regulated medications in palliative care at the end of life and record the level of pain endured by the 
patient. It is important that the whole philosophy of the clinician towards palliative care is based on a desire to keep the patient free of pain and that all words and actions reflect this [25].

Causing or hastening the death of an individual may give rise to criminal liability. The crime most likely to occur is 'murder'. This is illustrated when someone has induced (or accelerated) the death of a human and where there is an intention to kill. Although there are universal variations, it is crucial that criminal law normally treats predicting death as a likely result of acting as sufficient to constitute intent. When delivering palliative treatment, it is in the sense of this possible criminal obligation that the doctrine of double impact has gained some limited attention from the courts.

One could also argue that there is integrity and humanity at the core of the concept of the DDE: the recognition by the courts that no one can suffer in intractable pain even though the unintended outcome of highdose opioid administration is a shortening of life. However, it is possible to misapply the concept of double impact, leading to situations where opiates are administered to hasten death rather than alleviate pain [9].

\section{The Doctrine of Double-Effect and Neonatal Palliative Sedation}

Palliative sedation is a human right at the end of life and considered ethically acceptable for the control of refractory symptoms. It can be used in other situations: transiently for noxious procedures, during burn care, compassion extubation, emergency, respite and for psychological or existential suffering [26]. This procedure demands prudent use following an evidenced based approach. It is not euthanasia; the intention of the act and the desired result are different.

There is a dearth of literature around how the DDE is applied to neonatal palliative and end-of-life care. Other than the aforementioned Nuffield Report [18] it was difficult to locate mention of the DDE in neonatal palliative care guidelines. The newborn is at a greater risk of medication toxicity due to their immaturity, especially premature babies [27]. In the absence of palliative care expertise in the management of symptoms, apnea may rise as a concern in pain control and palliative sedation. In 2012, the South Central Palliative Care Group [28] stated an awareness that opiates may cause respiratory depression (citing the DDE), while emphasizing that there is no limit to the dosage of morphine for pain relief or discomfort, while being clear that it is never appropriate to resort to deliberate medically induced sedation at the end of life [28]. This raises the challenge of how to make DDE more transparent and useful in guiding the healthcare team.

There is, therefore, space for ethical distinction between procedures such as palliative sedation and physician-assisted-dying, even though a patient's life is shortened by sedation. This takes us to the most apparent Palliative Care ethos: pain relief. Such an aim varies from that of traditional medicine, which is geared toward health and disease recovery. Understanding the meaning of motive also makes it easier to differentiate between professionals in palliative care and those who might operate with the intention of ending patients' lives. This basic 
difference in purpose or mission makes a palliative care theory distinct. The DDE literature is clear in that narcotic analgesia should be prescribed for palliative purposes, stating four principles: Whether the essence of the act in itself is good; In prescribing narcotic analgesia, the purpose is to relieve pain and not to hasten death; While the patient is dying and suffering pain, the positive effect of pain relief outweighs the poor effect of death; and that the positive result is not accomplished by the negative effect (pain relief) (death) [29]. However, a number of palliative care experts have recently debated whether medications such as morphine, benzodiazepines and barbiturates really hasten death when administered as an analgesic, and thus whether the double-effect doctrine is still applicable to decisions of this kind. Sedatives or morphine use was not correlated with duration of life in a significant number of studies of palliative care patients. There is, also, evidence that, paradoxically, higher doses of opioids and sedatives in the intensive care unit are correlated with longer survival after extubation. Therefore, withholding analgesics owing to a fear of hastening death is doubly troublesome [30].

The Leonetti constitution in the USA sought to authorize the withholding or removal of treatments where they seemed to be unnecessary, disproportionate or had no effect other than artificial preservation of life. The Royal College of Pediatrics and Child Health argues that, given the limitation of medical procedures or therapies, in certain cases it is in the best interest of children: when life is limited in quantity or quality and when there is an educated qualified rejection [31].

In all situations, palliative care and pain management is essential even if intensive therapy is ceased. Anti-pain medicine is approved for patients at an advanced or final stage of serious and incurable affliction when appropriate, even though death may be accelerated as a side effect [32]. Appropriate pharmacological control designed to involve the usage of morphine for end-of-life treatment is important within the principles of opioid stewardship [33].

While not performed on neonates, several studies and analyses of opioids and sedatives worldwide are explicit that they do not hasten death or change survival, contrary to the assumption that opioids hasten death [34]. They do not hasten death when administered after removing ventilator assistance. Indeed, even in those completely dependent on mechanical support, because of their beneficial impact on respiratory function, opioids and benzodiazepines enable breathing to be more relaxed and to continue longer after ventilatory withdrawal [35].

For neonatal patients with intractable pain, healthcare professionals must ensure that the clinical need for the treatment is made clear to families and documented as to why the dosage needs to be titrated upwards. To ensure that too high a dose is not given, healthcare providers must continue to monitor the patient's discomfort, anxiety and reaction to analgesia. It is important that healthcare providers comply completely with the standards for documenting and prescribing regulated drugs in order to protect patients [9]. 
What lessons can neonatal palliative care take from the adult discipline? The experience of the adult hospice and palliative care movement over the past three decades has demonstrated that cause of death should not be challenged by the safe and efficient use of morphine, other opioids, and sedatives in pain and symptom management. There is no clinical research evidence in the adult literature that, if used with sufficient ability to treat symptoms, morphine causes death. Respiratory depressant effects, in particular, have been found to be negligible and the presence of pain tends to serve as an antagonist of respiratory depression and opioid sedative effects. However, opioids are harmful if used incorrectly, like any class of medications [17]. Despite ethical concerns about shortening the dying process, the right understanding of the DDE is clearly consistent with providing opioids to alleviate pain and other distressing symptoms, such as dyspnea, even if there are unintended effects, such as hypotension or hypoventilation [35]. Magnusson [21] argued that the traditional construction of palliative care relies on the concept of the DDE to protect clinicians from moral and legal liability for hastening death. However, if it is as morally and legally unethical to deliberately help people die as critics of physicianassisted dying argue, then the distinction between palliative care and illegal 'killing' needs to be clearer. It was a good first step to move beyond the concept of double impact, because while the DDE accepts the problem of the clinician, it fudges the moral value of therapeutic procedures and leaves the patient at the mercy of motives and intentions that can rarely, if ever, be challenged [21].

Two criteria Magnusson [21] argued, are necessary for palliative care procedures that conform with agreed and accountable professional practice, while allowing for accepted and responsible professional practice to justify compassionately driven treatments rather than the 'illusory' language of what the clinician claims they meant. In order to properly understand the gravity and implications of these end-of-life choices, laws and ethics. It is reasonable to impute to the clinician an intention to hasten death in cases where the provision of symptom relief is highly probable or indeed certain to shorten the life of a patient. This does not mean that euthanasia is accepted as a standard part of palliative care by legislation or medical ethics: it is the surreptitious, undeclared practice of euthanasia that justifies the criticism of traditional palliative care accounts. It is, however, to admit that clinicians often have to face the choice of the devil: a choice, that is, between relieving suffering and inadvertently accelerating death in situations where there is no third option and where it is difficult not to choose. Finally, in accordance with the proposed defense of necessity, if the clinician has administered known analgesic drugs in dosages that were a proportionate response to the patient's pain, the conduct of the clinician would be justified [21].

It is suggested that to ensure that the use of high-dose opioids or palliative sedation is sufficient, the interdisciplinary team should confirm that precautions are in place. Have all reversible reasons been investigated for the extreme symptoms? Have any other possibilities for treatment been attempted or examined? Were all other tools considered? Has there been informed consent and evidence of that 
consent in the medical record? An interdisciplinary approach to teams means that all choices are taken into account.

The principle of the proportionate use of drugs is a fundamental premise of DDE; the dosage of opioids and/or sedatives should be the lowest dose required to achieve the purpose of symptom relief. Proportional palliative care supporters encourage clinically appropriate, symptom-guided and carefully controlled sedation.

The DDE may have value in guiding clinicians in palliative sedation in the newborn care unit. For example, in adult medicine, opioids may be offered to a terminally ill patient for the relief of pain or dyspnea, often at the cost of side effects, such as sedation, respiratory distress, hypotension, and potentially hastening of death. We need to ask ourselves whether hastening death should be perceived as killing, when the purpose is actually to alleviate intractable pain. DDE encourages the healthcare team to provide neonatal patients with sufficient palliative treatment, even though it may lead to their death, while also resisting physician-assisted suicide and euthanasia. It is, however, difficult to cope with the 'moral uncertainty' which occurs in cases where prudential judgment is at an impasse even when intentions are 'good'.

But does intention matter?

\section{Exploring the Ethical Quagmire of Double-Effect in Neonatal Palliative Care}

One's intent should matter. Genuis [20] argues that it is axiomatic to say nothing about ethics in a wider context. Western medicine does not maintain this assertion alone to assess ethical correctness, considering instead the increasing prevalence of iatrogenic diseases and the unusual but lethal side effects or complications of several common pharmacological agents and surgical procedures. In addition, both patient-centered-care models and the four-principle thesis of Beauchamp and Childress, which is so often quoted as the cornerstone of biomedical ethics, depend on the fundamental value of beneficent intent in healthcare [20]. Simply put: the purpose of the clinician matters if our current bioethical debates are to be intelligible at all. And if intent matters, then the idea of the DDE serves as a cogent distinction in endof-life treatment ideologies.

Long-informed Western medical practice has the concept of the DDE perhaps most recognizably in end-of-life cases, where a practitioner frequently faces the difficult option of prescribing palliative treatment (e.g., opioid analgesics) recognizing that the death of the patient can therefore be accelerated. Despite its long use, both clinicians and bioethicists critical of its role in endorsing what they consider to be unfair laws banning physician-assisted suicide have recently experienced a sharp attack on the concept of the DDE. That, at least, is a philosophical view commonly held, and in many jurisdictions, it is believed to underpin the law. Without a strong distinction between intent and foresight, it is difficult to invoke the DDE to neatly separate correct actions from incorrect ones. Moral theory arguments are now being put to the test steadily, and some claims have been found lacking. 
The DDE Theory is proving to be an idealized and somewhat impractical account of the way people reason (as many have previously argued) [36].

Lombard [37] implies that it is wrong to talk of a single double effect doctrine. Instead, on the meaning and implementation of the doctrine, there are various viewpoints. A clear understanding is that it is a doctrine that 'distinguishes between the intended effects and those that might be foreseen but not intended.' Therefore, in situations where the behavior of a healthcare professional in the administration of palliative sedation appear to exhibit some of the characteristics usually associated with it, double effect is called upon as a justification. In this respect, it is indicated that the focus on 'academics and professionals' is better explained by its immense practical usefulness' [37].

Despite criticisms about the DDE the concept continues to be used (and taught) in medical decision making. The deontological component of Western medical morality, captured in the nonmaleficence theory, is one: 'First do no harm.' If a deontological element is present, the concept of the DDE arises and is often part of any working professional ethics, especially those with an explicit code (e.g. nurses, doctors). A second explanation closely follows: that of professional identification. The meaning of the DDE theory, then, is essentially embedded in our sense of professional competence (the doctor as healer; the nurse as an advocate), which inevitably gives rise to concerns when faced with an intervention that has adverse consequences (i.e. 'other-than healing'). The DDE is not a mechanism of decision-making that promises simple answers to tough situations. However, to the degree that it embodies a concern for our identity as healers, it offers a richer and more fruitful method than either the minimalist or maximalist methods described in this section to describe the moral obligations of clinicians.

Similarly, Tervo and Wojda [38] proposed the need to change the DDE so that it could be flexibly used. Their proposal considered not merely a choice between a single good and a bad outcome, but between various 'goods' and 'bads'. The choice is not the cold calculus of a consequentialist, but a choice that becomes a proportional choice between results when judged qualitatively, which aspires to a primarily positive effect and 'avoids bad'. It is important for a clinician to consider dilemmas and to bring their moral questions into a structured conversation with the patient (in this context, the baby's family). An updated DDE is thought to be a valuable way of deliberating on these moral events [38].

Some elements of the double-effect doctrine do not seem to be well known. The first condition, for a start, that the act itself is not bad, seems elusive to many writers and is therefore viewed only cursorily if not fully ignored. Second, the role of purpose is frequently, if not ignored, greatly understated [39]. For both of the first two conditions, Murphy [39] argues that purpose is important. It is applicable to the second (that the evil effect might not be intended) in a very obvious way, as it needs to be clearly stated in some way by some accurate version of the second condition. However, it is also applicable to the former, since the act under consideration here is a deliberate individual [39]. 
The literature on the current importance of DDE remains divided. With historical influence and ongoing support, DDE has inherent philosophical significance. However, the applicability of DDE in Palliative Care is uncertain (because adequate management of symptoms does not trigger death); inconsistencies contradict the presumed need (DDE is not needed to 'cover' prescribers in neutropenic sepsis deaths due to chemotherapy); and DDE allows possible harm (unintentionally providing a medical protection if a fatal opioid overdose is purposely administered) sufficient to A better principle for directing clinicians seems to be 'Best Practice' [7].

Braude [40] argued that the study of DDE in terms of liminality provides a way to show how liminal structures can be integrated into ethical thinking in palliative care through phronesis. The challenge in articulating a simple set of standards of ethics for palliative care stems from the basic sense of palliative care, which is one of 'liminality.' Liminality is an anthropological term that refers to biological and social transformations and their associated ritual processes. The theory of liminality has also been extended to the experience of serious illness and the context of the end of life. However, the importance of liminality in the ethics of palliative care has not yet been clearly articulated. This is perhaps surprising, because the construction of normativity is synonymous with liminality. Indeed, liminality is characterized by the overturning of daily norms and definitions as a philosophically laden anthropological notion.

\section{The Doctrine of Double-Effect and Implications for Neonatal Palliative Care Practice.}

What does the DDE achieve? If anything, it recognizes that end-of-life treatment imposes difficult decisions and requires clinicians both to minimize pain and potentially hasten death in cases where opioids or sedation at the end of life may interfere with the moment of death.

In the context of neonatal palliative care, if a newborn dies after being given a correct dose of morphine to relieve pain, then the death of the baby can be considered a 'bad side effect' at least according to the concept of DDE.

Because as clinicians we are motivated by compassion and empathy, we may do what is good and right by a patient, but we may also do what is good and right by a patient because we are motivated by fear of litigation. Although we do what is good and right in both situations, our moral characters are changed by the reasons we act on. Importantly, motivation often influences the reliability (or otherwise) of the moral actions of a person; for example, the sufficiently vigilant clinician who normally acts out of empathy and compassion can be counted on to do what is fair and right by her or his colleagues and patients, while the clinician who acts out of fear of the law may be less reliable in situations where, for example, there are no witnesses to their actions. In this sense, in moral deliberation, motivations have a significant role to play, but they do not alter the character of other elements of moral deliberation, such as intention. 
It is possible to see that if an intention is bad in itself (such as (doing something actively with the intention to hasten death) when seen within the sense of conventional morality, then the conduct that accompanies this intention is also morally wrong. If, however, one intends that which is good (such as pain relief), then the action that accompanies this purpose is indeed morally good, considering all else, even if it results in the bad side effect of death.

Similarly, if the clinician acts on the presumption that, in the absence of any desire to cause death, they relieves pain, then the clinician does nothing wrong, morally speaking, should the patient die because they acted incompetently by, for example, negligently prescribing opiates and sedation such that the prescribed doses are disproportionate to the pain and/or agitation experienced. They are correctly considered both morally and legally irresponsible to the degree that a clinician prescribes opiates and sedation incompetently. Nevertheless, in the absence of an attempt to 'kill' it might be stretching the moral argument to characterize that same clinician, incompetent as they may be, as an actual 'murderer'; a finding of incompetence is not morally equivalent to a finding of murder.

Importantly, within a tradition that places the greatest store on the agent's moral psychology, the DDE was formulated; for this reason, the position of intention is of utmost importance. In other words, when we act in one way or another, it is a tradition in which ethical analysis focuses on deciding what we make of ourselves: who we become, morally speaking. Clinicians who are adamant on alleviating the pain and suffering of their neonatal patients are the clinicians who are therefore believed to make themselves healers, even in the unlikely event that palliative medication can interfere to shorten the lives of patients. In other words, the moral emphasis is on the individual who acts, and not simply on the result of the actions of that person, essential as they may be.

\section{Conclusions}

The DDE is a source of contention and vigorous discussion because of the inherent uncertainty surrounding the idea that if pain is present, although an earlier death might not be expected, it may also be considered a good result. Providers of treatment may have mixed emotions about the death of a patient, regardless of where they are situated on the continuum of life, whether at the beginning, or the end. The DDE remains an ethical and legal quagmire in the care of the terminally ill, amid these ambiguities.

Caring for neonates at the end of life who are suffering is, without doubt, a stressful undertaking. Instead of avoiding ethical discussions out of fear, ethical confusion, or legal consequences, the neonatal healthcare team should note that such introspection is required by our underlying compassion and conscience.

It is important that there is a framework in which questioning clinicians can discuss their ethical issues, including the DDE. All healthcare 
professionals need to become more familiar with their boards, procedures, and tools for institutional ethics review.

Palliative care plays an important role in ethical decision making when applying DDE to neonatal care. Advocacy for palliative care in the neonatal unit, universal health coverage of services and education for professionals involved in the care of newborns and their families, can guide professionals when facing difficult decisions.

Author Contributions: VK and JM participated equally in the conceptualization, writing, editing, and final approval of this review. All authors have read and agreed to the published version of the manuscript.

Funding: This research received no external funding.

Conflicts of Interest: The authors declare no conflict of interest.

\section{References}

[1] J. Mendes Branquinho, Da vulnerabilidade do recém-nascido aos cuidados paliativos neonatais. Cadernos de Bioética 19 (2011) 161-172.

[2] A. Catlin, D. Brandon, C. Wool, and J. Mendes, Palliative and End-of-Life Care for Newborns and Infants: From the National Association of Neonatal Nurses. Advances in neonatal care 15 (2015) 239-240.

[3] V. Kain, and S.D. Chin, Conceptually Redefining Neonatal Palliative Care. Advances in Neonatal Care 20 (2020).

[4] T.A. Cavanaugh, Double-Effect Reasoning: Doing Good and Avoiding Evil, Oxford University Press, 2006.

[5] R. Twycross, Reflections on palliative sedation. Palliative Care: Research and Treatment 12 (2019) 1178224218823511.

[6] O.N. Griese, Catholic Identity in Health Care: Principles and Practices, Natl Catholic Bioethics Center Washington DC, 1987.

[7] C. Gannon, Systematic review on the doctrine of double effect within palliative care. BMJ Supportive \& Palliative Care 9 (2019).

[8] S. Duckett, and S. Duckett, Knowing, Anticipating, Even Facilitating but Still not Intending: Another Challenge to Double Effect Reasoning. Journal of bioethical inquiry 15 (2018) 33-37.

[9] J. Chalmers, The true meaning of wicked recklessness: Hm advocate purcell. Edinburgh Law Review 12 (2008) 298-302.

[10] World Health Organization, Guidelines on the management of chronic pain in children. available at https://www.who.int/publications/m/item/guideline-for-the-management-of-chronic-painin-children Maternal, Newborn, Child and Adolescent Health and Ageing (MCA) Department (2020).

[11] L. Fraser, D. Gibson-Smith, S. Jarvis, P. Norman, and R. Parslow, 'Make Every Child Count' Estimating current and future prevalence of children and young people with life-limiting conditions in the United Kingdom. University of York report available at https://www.york.ac.uk/media/healthsciences/documents/research/publichealth/mhrc/Prevalence\%20reportFinal.pdf (2020).

[12] Perinatal Hospice \& Palliative Care, List of programs. available at. https://www.perinatalhospice.org/list-of-programs. (2021).

[13] V.J. Kain, The Praecox Program: Pilot testing of an online educational program to improve neonatal palliative care practice. Journal of Neonatal Nursing 23 (2017) 188-192.

[14] N. Arias-Casais, E. Garralda, J.J. Pons, J. Marston, L. Chambers, J. Downing, J. Ling, J.Y. Rhee, L. de Lima, and C. Centeno, Mapping Pediatric Palliative Care Development in the WHO- 
European Region: Children Living in Low-to-Middle-Income Countries Are Less Likely to Access It. Journal of pain and symptom management 60 (2020) 746-753.

[15] C.A. Fortney, and D.K. Steward, Medical Record Documentation and Symptom Management at the End of Life in the NICU. Advances in neonatal care: official journal of the National Association of Neonatal Nurses (2014).

[16] R. Drake, R. Hain, McNamara K., and B. Nkosi, International Children's Palliative Care Network (ICPCN) Position Statement on the Practice of Euthanasia and Assisted Suicide. International Children's Palliative Care Network available at http://www.icpcn.org/wpcontent/uploads/2013/07/ICPCN-Position-Statement-on-Euthanasia-and-Physician-AssistedDeath-in-Children.pdf (2017).

[17] B.P. White, L. Willmott, and M. Ashby, Palliative care, double effect and the law in Australia: Palliative care, double effect and law. Internal medicine journal 41 (2011) 485-492.

[18] A. Winyard, The Nuffield Council on Bioethics Report - Critical care decisions in fetal and neonatal medicine: Ethical issues. Clinical risk 13 (2007) 70-73.

[19] C. April, and M. Parker, End of life decision-making in neonatal care. Journal of medical ethics 33 (2007) 126-127.

[20] Q.I.T. Genuis, Trust, intent, authenticity, and good dying: Beyond the autonomy debates and towards a philosophy of palliative care. Progress in palliative care 25 (2017) 286-290.

[21] R.S. Magnusson, The Devil's Choice: Re-Thinking Law, Ethics, and Symptom Relief in Palliative Care. The Journal of law, medicine \& ethics 34 (2006) 559-569.

[22] A. Verhagen, and P. Sauer, End-of-life decisions in newborns: an approach from the Netherlands. Pediatrics 116 (2005) 736-739.

[23] L. Dombrecht, L. Deliens, K. Chambaere, S. Baes, F. Cools, L. Goossens, G. Naulaers, E. Roets, V. Piette, J. Cohen, K. Beernaert, N. Consortium, N. consortium, and N.c. the, Neonatologists and neonatal nurses have positive attitudes towards perinatal end - of - life decisions, a nationwide survey. Acta Paediatrica 109 (2020) 494-504.

[24] S.A. Trankle, Decisions that hasten death: Double effect and the experiences of physicians in Australia. BMC medical ethics 15 (2014) 26-26.

[25] R. Griffith, Controlled drugs and the principle of double effect: the role of the district nurse. British journal of community nursing 21 (2016) 633-635.

[26] N.I. Cherny, and L. Radbruch, European Association for Palliative Care (EAPC) recommended framework for the use of sedation in palliative care. Palliative medicine 23 (2009) 581-593.

[27] S. Jassal, Symptom control in paediatric palliative care. Paediatrics and child health 26 (2015) 8788.

[28] South Central Palliative Care Group, Neonatal Palliative Care Guideline based on UHS Neonatal Palliative (Supportive \& End of Life) Care Guideline. http://www.networks.nhs.uk/nhsnetworks/south-central-neonatalnetwork/documents/guidelines/Neonatal\%20Palliative $\% 20$ care $\% 20$ guideline.FINAL.pdf (2012).

[29] H. McCabe, End-of-life decision-making, the principle of double effect, and the devil's choice: a response to Roger Magnusson. Journal of law and medicine 16 (2008) 74-84.

[30] D. Wilkinson, Three myths in end-of-life care. Journal of Medical Ethics 39 (2013) 389.

[31] V. Larcher, F. Craig, K. Bhogal, D. Wilkinson, and J. Brierley, Making decisions to limit treatment in life-limiting and life-threatening conditions in children: a framework for practice. Archives of disease in childhood 100 (2015) s1-s23.

[32] M. Cuttini, V. Casotto, U. de Vonderweid, M. Garel, L.A. Kollée, and R. Saracci, Neonatal end-oflife decisions and bioethical perspectives. Early Human Development 85 (2009) S21-S25.

[33] World Health Organization, The Global Atlas of Palliative Care. 2nd edition available at http://www.thewhpca.org/resources/category/global-atlas-of-palliative-care-at-the-end-of-life (2020). 
[34] M. López Saca, and C. Centeno, Reaffirming the benefits of morphine to beat opiophobia. European journal of palliative care 22 (2015) 288-291.

[35] R. George, and C. Regnard, Lethal opioids or dangerous prescribers? Palliative Medicine 21 (2007) 77-80.

[36] C.D. Douglas, I.H. Kerridge, and R.A. Ankeny, Double Meanings Will Not Save the Principle of Double Effect. The Journal of Medicine and Philosophy: A Forum for Bioethics and Philosophy of Medicine 39 (2014) 304-316.

[37] J. Lombard, Law, palliative care and dying: legal and ethical challenges, Routledge Taylor \& Francis Group, Abingdon, Oxon;New York, NY; 2018.

[38] R.C. Tervo, and P. Wojda, The Principle of Double Effect, Genetic Testing, and Global Developmental Delay. Journal of child neurology 24 (2009) 1030-1036.

[39] J.G. Murphy, The principle of double effect: Act-types and intentions. International philosophical quarterly 53 (2013) 189-206.

[40] H. Braude, Normativity unbound: Liminality in palliative care ethics. Theoretical medicine and bioethics 33 (2011) 107-22. 